\title{
Fluid-Solid Heat Exchange in Porous Media for Transpiration Cooling Systems
}

\author{
Tobias Hermann, Matthew McGilvray $\dagger$ Hassan Saad Ifti $\stackrel{\ddagger}{\ddagger}$ \\ The University of Oxford, Department of Engineering, Osney Mead, The Southwell Building, \\ Oxford OX2 OES, United Kingdom
}

Fabian Hufgard ${ }^{\S}$ and Stefan Löhleף

Universität Stuttgart, Institut für Raumfahrtsysteme, Pfaffenwaldring 29, D-70569 Stuttgart, Germany

This paper presents a semi-analytical solution of the coupled differential equations for fluid and solid phase in a one-dimensional porous medium in thermal non-equilibrium. The thermal impulse response of the fluid and solid phases is used to determine the pressure loss over the thickness of the material. Experimental data obtained from surface heating of porous $\mathrm{ZrB}_{2}$ samples is compared to the theoretical model. The plenum pressure, surface temperature and backside temperature are measured using pressure sensors, thermographic imaging and thermocouple instrumentation The non-integer system identification (NISI) approach is used to obtain the thermal impulse response which is then compared with the model prediction. Plenum pressure rise and thermal impulse response of the heating experiments are used to assess the volumetric heat transfer coefficient of the sample. Good agreement is found between the simulated and experimental data for the temperature and pressure measurements. The obtained heat transfer coefficients are between $2.1 \cdot 10^{4}$ and $6.8 \cdot 10^{4} \mathrm{~W} \mathrm{~m}^{-3} \mathrm{~K}^{-1}$ for mass fluxes of 10 to $244 \mathrm{~g} \mathrm{~m}^{-2} \mathrm{~s}^{-1}$.

\section{Nomenclature}

a Heat loss constant, $\mathrm{W} \mathrm{m}^{-3} \mathrm{~K}^{-1}$

$A$ Coefficient in Laplace-space

$B \quad$ Coefficient in Laplace-space

$c_{p} \quad$ Specific heat capacity, $\mathrm{J} \mathrm{kg}^{-1} \mathrm{~K}^{-1}$

$C$ Coefficient for analytical temperature solution, $\mathrm{K}$

$C_{\text {ref }}$ Sutherland's constant, $\mathrm{K}$

$d \quad$ Length of square illuminated by the laser radiation

$H \quad$ Impulse response, $\mathrm{K}$

$h_{v} \quad$ Volumetric heat transfer coefficient, $\mathrm{W} \mathrm{m}^{-3} \mathrm{~K}^{-1}$

$J \quad$ Iteration parameter

$k \quad$ Thermal conductivity, $\mathrm{W} \mathrm{m}^{-1} \mathrm{~K}^{-1}$

$K_{D} \quad$ Darcy coefficient, $\mathrm{m}^{2}$

$K_{F} \quad$ Forchheimer coefficient, $\mathrm{m}$

$L \quad$ Thickness, $\mathrm{m}$

$M \quad$ Iteration parameter

$m \quad$ Mass, $\mathrm{kg}$

$\dot{m} \quad$ Mass flow, $\mathrm{kg} \mathrm{s}^{-1}$

$\dot{m}_{A} \quad$ Mass flux, $\mathrm{kg} \mathrm{m}^{-2} \mathrm{~s}^{-1}$

* Post-doctoral research assistant, Hypersonics group, Oxford Thermofluids Laboratory, AIAA Member.

${ }^{\dagger}$ Assistant Professor, Head of hypersonics group, Oxford Thermofluids Laboratory, AIAA Member.

${ }^{\ddagger} \mathrm{PhD}$ student, Hypersonics group, Oxford Thermofluids Laboratory, AIAA Member.

$\S$ PhD student, High Enthalpy Flow Diagnostics Group, Institute of Space Systems.

\Research engineer, Head of High Enthalpy Flow Diagnostics Group, Institute of Space Systems, AIAA Member. 


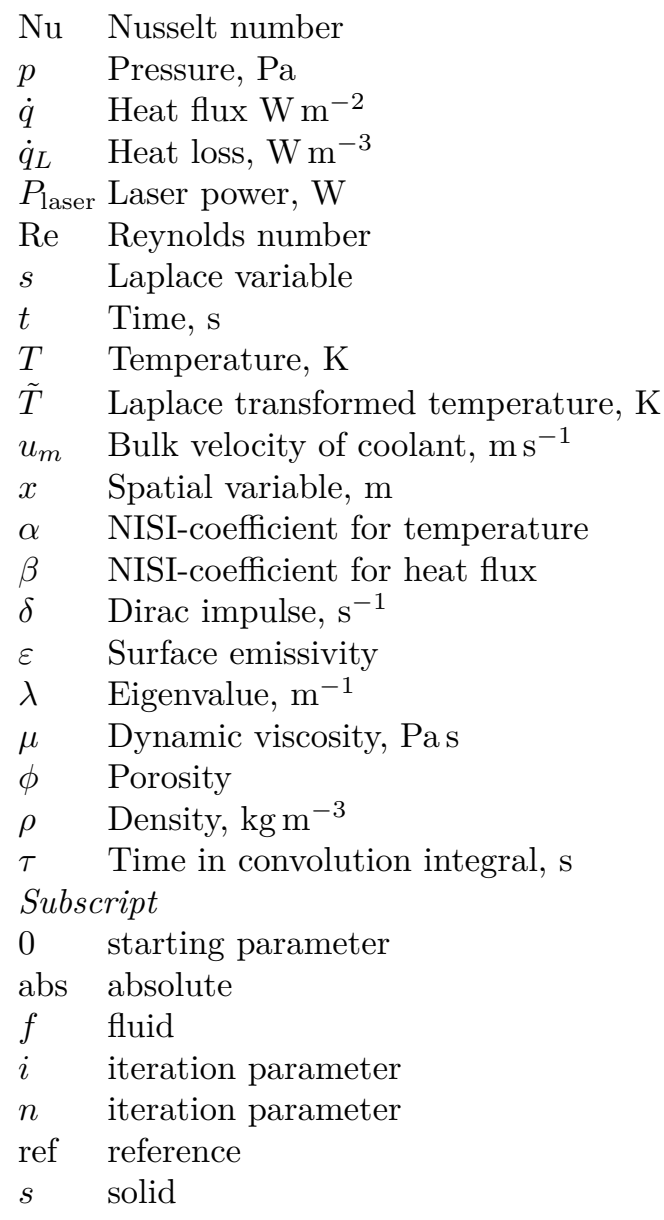

\section{Introduction}

Porous media are a centrepiece of actively cooled thermal protection systems for future hypersonic vehicles that are exposed to heat fluxes that cannot be managed by passive cooling. ${ }^{1-7}$ Thermal management of wall temperatures and absorbed heat load of re-entry vehicles or hypersonic cruise vehicles is one of the major challenges of such systems. ${ }^{8}$ Porous media are envisaged to enable transpiration cooling, where relatively cool fluid is fed through a porous wall of said vehicles. ${ }^{9-13}$ There are two primary cooling mechanisms: The gas exiting the porous wall forms a coolant layer between hot external flow and the wall which reduces the aerodynamic heat load experienced by the vehicle. This effect leads to lower boundary layer temperatures and inhibits surface recombination and oxidation reactions. ${ }^{14,15}$ Furthermore, the convective heat exchange between the hot solid phase and the colder fluid phase within the porous medium leads to the cooling of the entire wall segment. ${ }^{16-19}$ This paper aims to investigate the latter of the two cooling mechanisms.

One important detail for the understanding of transpiration cooling is the modelling of heat exchange inside the material between solid and fluid. The efficiency of heat exchange between these two phases is quantified by a volumetric heat transfer coefficient $h_{v} \cdot{ }^{16}$ It is an important design parameter for transpiration cooled heat shields and hence an important property for various candidate materials. Furthermore, the coupling between fluid and solid phases leads to secondary effects that need to be taken into consideration for the design of this type of cooling system, i. e. an elevated fluid temperature leads to an increase in viscosity which in turn results in a reduced mass flow rate when the pressure difference over the material is held constant. ${ }^{20}$ The investigation of the fluid-solid heat transfer, thus, has an immediate effect on the possible maximum coolant flow rate of a real system. Apart from transpiration cooling systems, this efficiency is also used in ablative material models where the heat exchange between pyrolysis gas and carbon fibres occurs in the char layer. ${ }^{21-23}$

Existing methods to characterise $h_{v}$ of a particular material can be found in Refs. ${ }^{24-30}$ The methodology 
of these approaches relies on measuring the transient solid and fluid temperatures of a porous material exposed to a heated flow which is passing through it. A numerical or analytical model of the material using the known thermophyscial parameters is then employed to assess the volumetric heat transfer coefficient. An alternative approach consists of the transient heating (e. g. by radiation or electrical current) of the solid phase instead. ${ }^{22,23,31}$ The present work uses a radiative heating technique, but a new approach to identify the volumetric heat transfer coefficient from the measurements is developed by analysing the thermal impulse response and the transient plenum pressure.

The impulse response of a particular linear thermal system, i. e. constant thermophysical parameters, is unique and hence describes the thermal behaviour of it completely. ${ }^{32}$ An impulse response describes the transient temperature trace at a certain location within a material which has been subject to a heat flux impulse, usually imposed at the surface. The heat flux is defined as a Dirac impulse at time $t=0$ which has an amplitude of infinity and an integral of $1 \mathrm{~J} \mathrm{~m}^{-2}$. An example of a surface temperature impulse response of a semi-infinite material is shown in Fig. $1 .{ }^{33}$ As will be shown, $h_{v}$ has a significant influence on the thermal impulse response of a porous medium. The thermal impulse response of a system is the central requirement for the analysis of inverse heat conduction problems, i. e. for heat flux measurements based on in depth or surface temperature measurements. ${ }^{34,35}$ Analytical analyses of the coupled differential equations have been conducted in Refs. ${ }^{25,36}$ This paper presents the theoretical derivation of the impulse responses for solid and fluid phases. Furthermore, the developed theory is applied to assess the volumetric heat transfer coefficient of a porous $\mathrm{ZrB}_{2}$ sample.

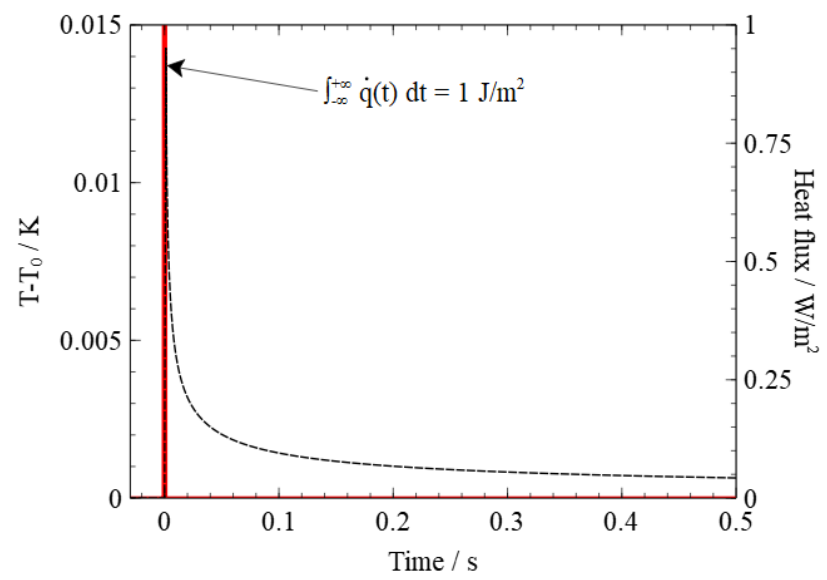

Figure 1. Example of a heat flux impulse and the respective surface temperature impulse response for a semi-infinite one-dimensional case.

\section{Theory}

The coupled partial differential energy equations of a porous medium are solved to deduce the temperature response of solid and fluid phases which can be in thermal non-equilibrium due to a unit impulse of heat at the surface. The one-dimensional energy equation for the solid phase is

$$
\underbrace{(1-\phi) \rho_{s} c_{p, s} \frac{\partial T_{s}}{\partial t}}_{\text {Transient heating (solid) }}=\underbrace{k_{s}(1-\phi) \frac{\partial^{2} T_{s}}{\partial x^{2}}}_{\text {Conduction (solid) }}+\underbrace{h_{v}\left(T_{f}-T_{s}\right)}_{\text {Fluid solid heat exchange }}+\underbrace{\dot{q}_{L}}_{\text {Heat loss }}
$$

and the respective energy equation for the fluid phase is

$$
\underbrace{\phi \rho_{f} c_{p, f} \frac{\partial T_{f}}{\partial t}}_{\text {Transient heating (fluid) }}=\underbrace{\phi \rho_{f} c_{p, f} \frac{u_{m}}{\phi} \frac{\partial T_{f}}{\partial x}}_{\text {Convection }}+\underbrace{h_{v}\left(T_{s}-T_{f}\right)}_{\text {Solid fluid heat exchange }}
$$

with spatial location, $x$, time, $t$, porosity, $\phi$, solid $(s)$ and fluid $(f)$ density, $\rho$, specific heat capacity, $c_{p}$, thermal conductivity, $k$, fluid bulk velocity, $u_{m}$, heat loss term, $\dot{q}_{L}$ and temperature difference, $T=\left(T_{\text {abs }}-T_{0}\right){ }^{25}$ 
Here, $T_{0}$ is the starting temperature and $T_{\mathrm{abs}}$ is the absolute temperature. The inclusion of a heat loss term $\dot{q}_{L}$ represents the inevitable lateral heat conduction in a non-adiabatic experimental setup, an approach which has previously been used by Langener. ${ }^{9}$ The lateral heat loss is assumed to be dominated by conduction in the solid phase, since the thermal conductivity of the fluid phase is negligibly small. The small thermal conductivity of the fluid is also the reason for omitting any conduction terms in Eq. (2). The heat loss term is assumed to be of the form

$$
\dot{q}_{L}=a T_{s}
$$

with the constant $a$ to be determined from the particular experiment. This formulation assumes a constant temperature of the mount containing the porous piece (see section III for details of the experimental setup). The reason for this assumption is that the thermal mass $\left(c_{p} \cdot m\right)$ of the surrounding experiment is large compared to the thermal mass of the heated porous sample. Hence, heat conducted into the outer structure will not lead to a significant increase in its temperature. Therefore, the lateral conduction will be mostly driven by the solid temperature which is reflected in Eq. (3).

The corresponding boundary conditions for Equations (1) and (2) are

$$
\begin{gathered}
\text { Constant fluid temperature at backside } \\
\underbrace{x=L, \quad T_{f}(t)=0}_{\text {Adiabatic backside }} \\
\underbrace{x=L, \quad \frac{\partial T_{s}(t)}{\partial x}=0}_{\text {Heat Impulse on surface }}
\end{gathered}
$$

with thickness $L$ and Dirac impulse $\delta(t)$. For the solution of Eq. (1) and (2) it is assumed that the thermophyscial parameters $\rho, c_{p}$ and $k$ of both solid and fluid phase are not a function of temperature and constant throughout the material.

The solution of the coupled partial differential equations is achieved by applying a Laplace transform with respect to the time dimension. Eq. (1) and (2) reduce to

$$
s(1-\phi) \rho_{s} c_{p, s} \tilde{T}_{s}=k_{s}(1-\phi) \frac{\partial^{2} \tilde{T}_{s}}{\partial x^{2}}+h_{v}\left(\tilde{T}_{f}-\tilde{T}_{s}\right)+a \tilde{T}_{s}
$$

and

$$
s \phi \rho_{f} c_{p, f} \tilde{T}_{f}=\phi \rho_{f} c_{p, f} \frac{u_{m}}{\phi} \frac{\partial \tilde{T}_{f}}{\partial x}+h_{v}\left(\tilde{T}_{s}-\tilde{T}_{f}\right)
$$

with the Laplace variable $s$ and the Laplace-transformed temperature $\tilde{T}$. Here, it is assumed that the material is isothermal before the heat impulse is applied. Through differentiation of Eq. (7) with respect to $x$ and substitution, the coupled equations reduce to the third order ordinary differential equation

$$
A_{3} \frac{\partial^{3} \tilde{T}_{s}}{\partial x^{3}}+A_{2} \frac{\partial^{2} \tilde{T}_{s}}{\partial x^{2}}+A_{1} \frac{\partial \tilde{T}_{s}}{\partial x}+A_{0} \tilde{T}_{s}=0
$$

with the coefficients

$$
\begin{gathered}
A_{0}=\frac{h_{v}}{(1-\phi) \rho_{s} c_{p, s}} \frac{h_{v}}{\phi \rho_{f} c_{p, f}}-\left(s-\frac{a-h_{v}}{(1-\phi) \rho_{s} c_{p, s}}\right)\left(s+\frac{h_{v}}{\phi \rho_{f} c_{p, f}}\right) \\
A_{1}=\frac{u_{m}}{\phi}\left(s-\frac{a-h_{v}}{(1-\phi) \rho_{s} c_{p, s}}\right) \\
A_{2}=\frac{k_{s}}{\rho_{s} c_{p, s}}\left(s+\frac{h_{v}}{\phi \rho_{f} c_{p, f}}\right) \\
A_{3}=-\frac{u_{m}}{\phi} \frac{k_{s}}{\rho_{s} c_{p, s}}
\end{gathered}
$$


The solution of Eq. (9) is

$$
\tilde{T}_{s}=\sum_{i=1}^{3} C_{i} \exp \left(\lambda_{i} x\right)
$$

with eigenvalues $\lambda_{i}$ and coefficients $C_{i}$. Substitution of this solution into Eq. (7) yields the fluid temperature

$$
\tilde{T}_{f}=\sum_{i=1}^{3} C_{i}\left(\frac{s(1-\phi) \rho_{s} c_{p, s}}{h_{v}}+\frac{k_{s}(1-\phi)}{h_{v}} \lambda_{i}^{2}\right) \exp \left(\lambda_{i} x\right) .
$$

The eigenvalues $\lambda_{i}$ are calculated by solving the characteristic equation

$$
A_{3} \lambda_{1-3}^{3}+A_{2} \lambda_{1-3}^{2}+A_{1} \lambda_{1-3}+A_{0}=0 .
$$

The three boundary conditions Eqs. (4-6) and the three unknown coefficients $C_{i}$ form a linear system of equations that can be expressed as the following matrix form

$$
\left(\begin{array}{ccc}
B_{1} \exp \left(\lambda_{1} L\right) & B_{2} \exp \left(\lambda_{2} L\right) & B_{3} \exp \left(\lambda_{3} L\right) \\
\lambda_{1} \exp \left(\lambda_{1} L\right) & \lambda_{2} \exp \left(\lambda_{2} L\right) & \lambda_{3} \exp \left(\lambda_{3} L\right) \\
\lambda_{1} & \lambda_{2} & \lambda_{3}
\end{array}\right) \cdot\left(\begin{array}{c}
C_{1} \\
C_{2} \\
C_{3}
\end{array}\right)=\left(\begin{array}{c}
0 \\
0 \\
\frac{-1}{k_{s}(1-\phi)}
\end{array}\right)
$$

with

$$
B_{i}=\frac{s(1-\phi) \rho_{s} c_{p, s}}{h_{v}}+\frac{k_{s}(1-\phi)}{h_{v}} \lambda_{i}^{2}
$$

which can be solved either analytically or numerically. This yields an analytical solution in the Laplace space. However, a transformation back into the time domain has not been attempted. Instead, the algorithm of Gaver and Stehfest is used to numerically perform this operation for the real part of the temperatures calculated by Eq. (14) and (15). ${ }^{37,38}$ When $s=0$ (steady state) and $a=0$ (no heat loss) are used, the calculated temperatures coincide with the solution obtained by Schweikert et al. who solved the same equations for an adiabatic steady state case. ${ }^{18}$

\section{Experimental setup}

The experiments reported in this work have been performed with the High Enthalpy Flow Diagnostic Group (HEFDiG) at the Institute of Space Systems (IRS) of the University of Stuttgart. The test article of this investigation is a partially sintered $\mathrm{ZrB}_{2}$ sample with a thickness of $L=5 \mathrm{~mm}$, manufactured by the Department of Materials of Imperial College London. The corresponding material properties are summarised in Table 1. The sample shape is a square of $32 \times 32 \mathrm{~mm}$. It is mounted within a stainless steel plenum using a layer of cement as sealant and thermal insulation between the two materials. The sample's surface is heated by a laser (Laserline LDM500-100) with a maximum optical power of $540 \mathrm{~W} .{ }^{39,40}$ The laser heat load is homogeneously distributed over a $68 \times 68 \mathrm{~mm}$ area. The larger heated area is intended to minimise lateral conduction, as the porous sample and the surrounding steel plenum are heated. The backside of the sample is instrumented by a type $\mathrm{K}$ thermocouple which is glued to the porous sample. Both the input power and the thermocouple response are recorded with a LeCroy 24Xs-A oscilloscope while the front temperature is recorded by a FLIR A6751sc SLS thermographic camera. An example image of the thermographic measurement during a laser heating experiment is shown in Fig. 3. The gas which is fed into the plenum behind the porous sample is pure nitrogen and is controlled by a Bronkhorst $1 \mathrm{~g} \mathrm{~s}^{-1}$ mass flow controller. The transient pressure signal in the plenum is recorded using both a GEMS 3100 Series ( 0 - 40 bar) and a Kulite ETQ-12-375M-5barA pressure sensor. A photograph of the setup is shown in Fig. 2.

Table 1. Material properties of $\mathrm{ZrB}_{2}$.

\begin{tabular}{ccccccc}
\hline \hline$\phi$ & $k_{s}$ & $c_{p, s}{ }^{41}$ & $\rho_{s}$ & $K_{D}{ }^{42}$ & $K_{F}{ }^{42}$ & $\varepsilon^{43}$ \\
\hline $42 \%$ & $41.4 \mathrm{~W} \mathrm{~m}^{-1} \mathrm{~K}^{-1}$ & $437.6 \mathrm{~J} \mathrm{~kg}^{-1} \mathrm{~K}^{-1}$ & $6080 \mathrm{~kg} \mathrm{~m}^{-3}$ & $2.443 \cdot 10^{-14} \mathrm{~m}^{2}$ & $8.855 \cdot 10^{-8} \mathrm{~m}$ & 0.75 \\
\hline \hline
\end{tabular}




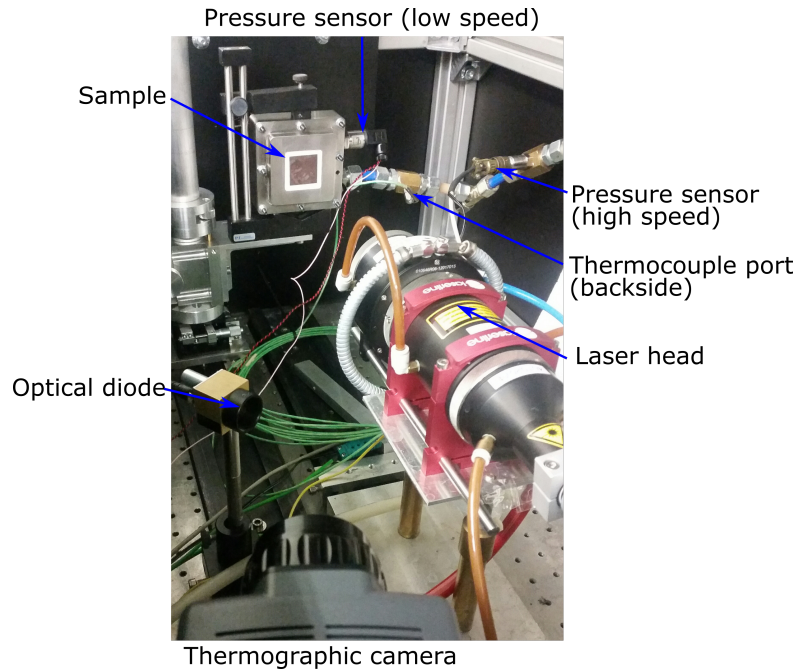

Figure 2. Overview of the experimental setup at IRS.

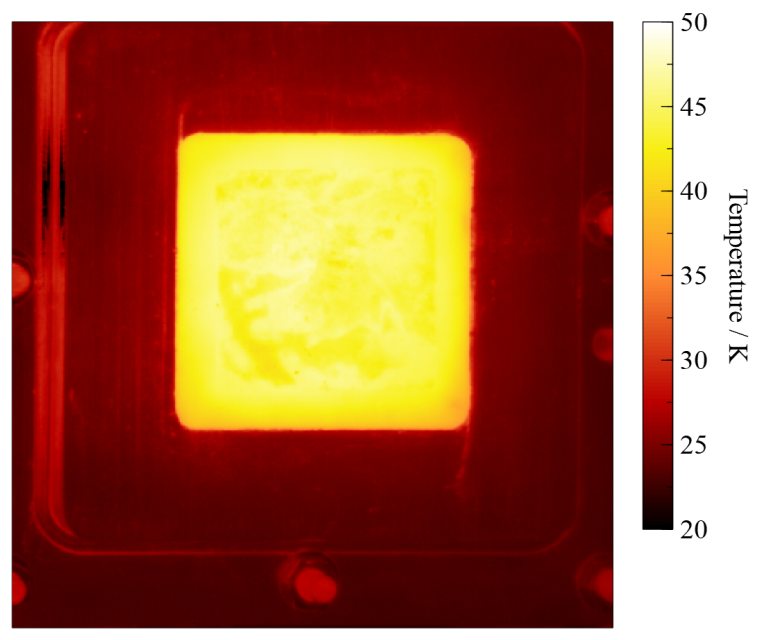

Figure 3. Example image of a thermography measurement.

\section{A. Phenomenological behaviour of the coupled solid-fluid system}

This section provides an overview of the phenomenological behaviour of the two phases within porous materials. The presented data are purely theoretical and are intended to highlight the physical processes that are exploited to analyse the efficiency of internal heat transfer in the conducted experiment. Simulated solid impulse responses $H_{s}$ are shown in Fig. 4 and the respective fluid impulse responses $H_{f}$ are shown in Fig. 5. These impulse responses have been obtained for $a=-2.71 \cdot 10^{4} \mathrm{~W} \mathrm{~m}^{-3} \mathrm{~K}^{-1}$ and a volumetric heat transfer coefficient of $h_{v}=3.5 \cdot 10^{4} \mathrm{~W} \mathrm{~m}^{-3} \mathrm{~K}^{-1}$. The heat loss parameter $a$ has been obtained by a best fit between experiment and simulation for the zero blowing case. Figure 4 shows that the temperature of the solid phase of the material equilibrates within approximately $1 \mathrm{~s}$, due to the high thermal diffusivity $k_{s} /\left(\rho_{s} c_{p, s}\right)$ of $\mathrm{ZrB}_{2}$. Heat is lost due to lateral conduction and the heat exchange with the fluid phase. This results in a steady decrease of the solid temperature until the solid phase essentially has been cooled down to the fluid backside temperature $\left(T_{s}=0\right)$.

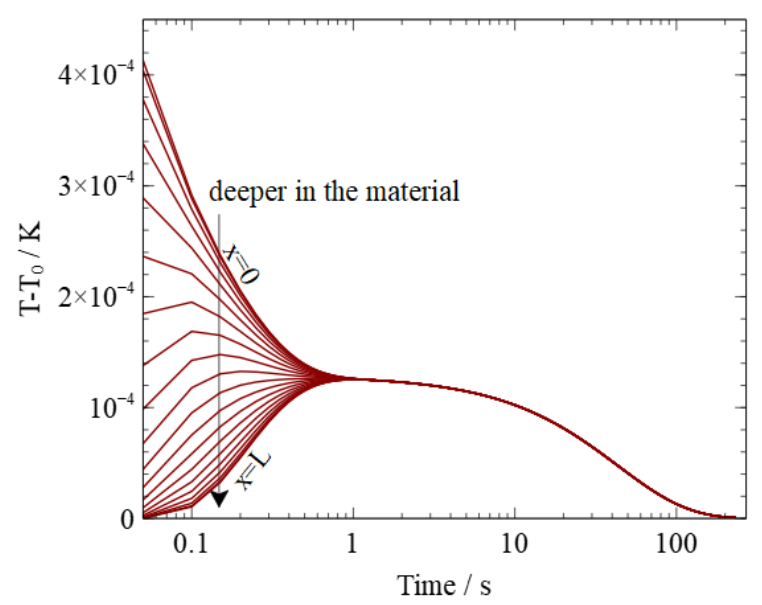

Figure 4. Thermal impulse responses of the solid material at various depths between 0 and $L$ in the material with $h_{v}=3.5 \cdot 10^{4} \mathbf{W} \mathbf{~ m}^{-3} \mathbf{K}^{-1}$.

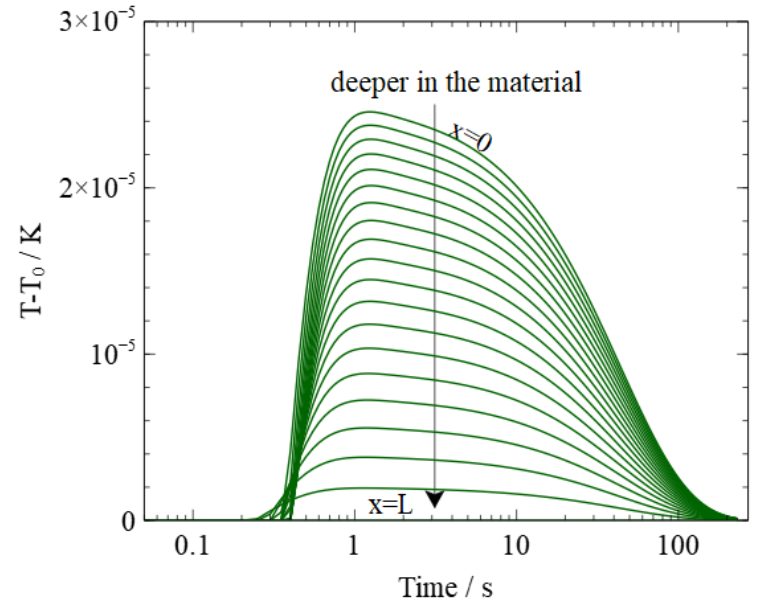

Figure 5. Thermal impulse responses of the fluid at various depths between 0 and $L$ in the material with $h_{v}=3.5 \cdot 10^{4} \mathbf{W} \mathbf{~ m}^{-3} \mathbf{K}^{-1}$.

Figure 5 shows that the fluid temperature is lagging behind the solid in both amplitude and phase, a con- 
sequence of the finite speed of heat transfer from solid to fluid, i. e. the cause of thermal non-equilibrium. The fluid entering the backside $(x=L)$ is at a temperature of $T_{f}=0$ (imposed by boundary condition (Eq. 4)). As the fluid is convected through the hot material, it receives more and more heat which leads to an increased temperature at the surface. The larger the heat transfer coefficient, the more equilibration between fluid and solid will occur. For $h_{v}=\infty$, the two impulse responses will be identical at a given depth in the material. This behaviour is highlighted in Fig. 6, where fluid and solid impulse responses are shown for various volumetric heat transfer coefficients. With increasing $h_{v}$, the solid and fluid impulse responses keep approaching each other, i. e. get closer to thermal equilibrium.

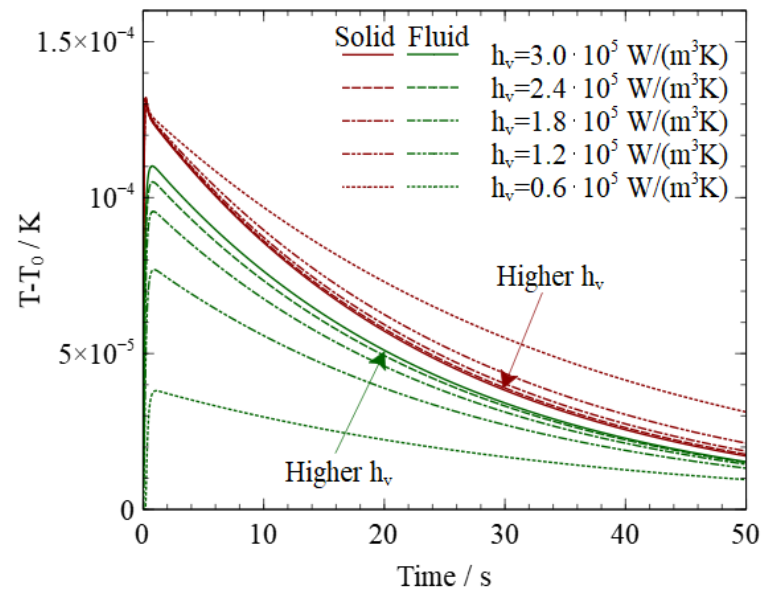

Figure 6. Fluid (green) and solid (red) impulse responses at $x=L / 2$ for $\dot{m}_{A}=0.186 \mathrm{~kg} \mathrm{~s}^{-1} \mathbf{m}^{-2}$ and various $h_{v}$.

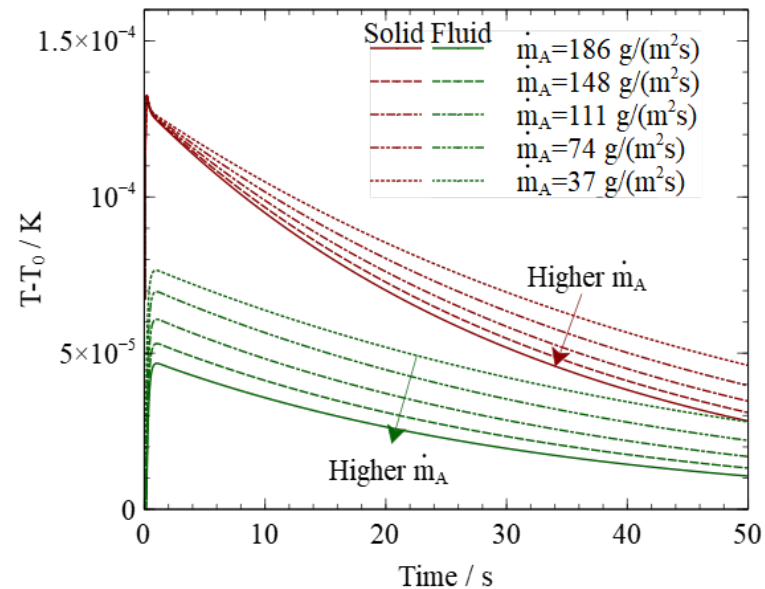

Figure 7. Fluid (green) and solid (red) impulse responses at $x=L / 2$ for $h_{v}=7 \cdot 10^{4} \mathbf{W} \mathbf{m}^{-3} \mathbf{K}^{-1}$ and various $\dot{m}_{A}$.

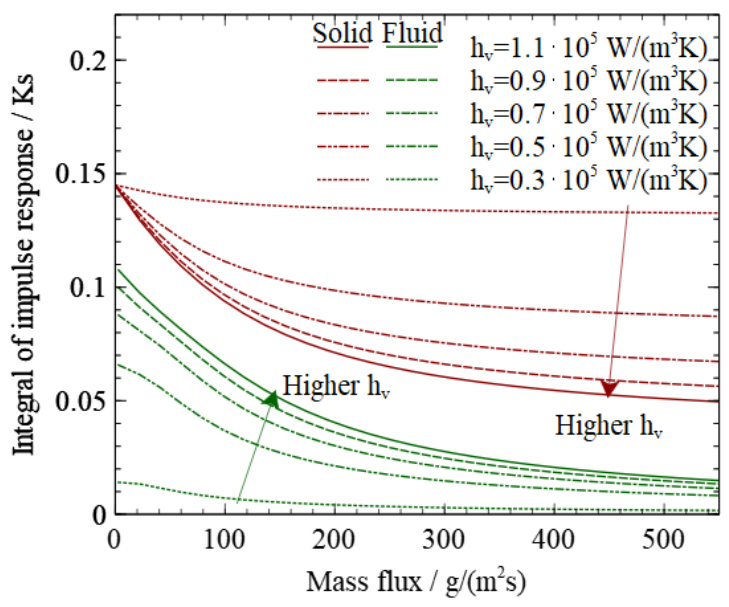

Figure 8. Integral of fluid (green) and solid (red) impulse responses at $x=L / 2$ for various $\dot{m}_{A}$ and various $h_{v}$

Figure 7 shows the effect of a varying mass flux on the impulse responses, ignoring that this would also increase $h_{v}$ in a real system. A higher mass flux will increase the thermal non-equilibrium between phases as the fluid has less time in which to equilibrate since it is convected at a higher speed. However, an increased coolant mass flow also leads to an increased cooling efficiency of the solid, and therefore a lower solid thermal impulse response. The cooling efficiency is further highlighted in Fig. 8 where the integral of the impulse responses are shown for various volumetric heat transfer coefficients and mass flow rates. The integral of an 
impulse response is indicative of the steady state temperature when the system is exposed to a unit step of heat flux. This is the case since a unit step (Heaviside function) is the integral of a Dirac-impulse. The plot shows that the sensitivity of solid phase cooling with respect to mass flux is very high for small mass fluxes since solid-fluid phase equilibration is easier to obtain at lower bulk velocities. Due to this, a state close to thermal equilibrium is present for low mass fluxes which results in a linear behaviour of the solid phase with respect to mass flux. For high mass fluxes, thermal non-equilibrium becomes more prominent which is the reason for a small gain in solid cooling when the mass flux is further increased. However, the volumetric heat transfer coefficient plays an important role in this regime since it promotes thermal equilibrium and hence increases the cooling efficiency, i. e. thermal non-equilibrium is delayed for higher volumetric heat transfer coefficients.

\section{Methodology}

The heat flux absorbed by the sample surface is calculated by

$$
\dot{q}(t)=\frac{\varepsilon P_{\text {laser }}(t)}{d^{2}}
$$

with the surface emissivity $\varepsilon$ and the laser power, $P_{\text {laser }}$, evenly distributed onto a square area with a length of $d=68 \mathrm{~mm}$. The corresponding measured temperatures (single thermocouple data, surface averaged thermographic data) and the deduced surface heat flux are used to infer the thermal impulse response of the material using the non-integer system identification (NISI) approach. ${ }^{40,44-46}$ Various non-integrer time derivatives of heat flux and temperature are used in the relation

$$
\sum_{m=M_{0}}^{M} \alpha_{m} \mathrm{D}^{m / 2} T(x, t)=\sum_{n=J_{0}}^{J} \beta_{n} \mathrm{D}^{n / 2} \dot{q}(x, t)
$$

to deduce the characteristic parameters $\alpha_{m}$ and $\beta_{n}$ for a given system. Therefore, the amplitude of the transient radiative heating is varied by discrete steps in a pseudo random way. ${ }^{44}$ Subsequently, the obtained parameters are used to calculate the thermal impulse response of the given temperature measurement location, i. e. the surface or the backside. This method has been applied to transpiration cooled materials in a previous investigation of Carbon-Carbon $(\mathrm{C} / \mathrm{C})$ samples. ${ }^{34}$ All impulse responses obtained by this approach are denoted as experimental for the remainder of this study. Figure 9 presents an example of the temperature fitting for the case of a mass flux of $\dot{m}_{A}=205 \mathrm{~g} \mathrm{~m}^{-2} \mathrm{~s}^{-1}$. An excellent agreement between the NISI-identification and the measurement data is obtained.

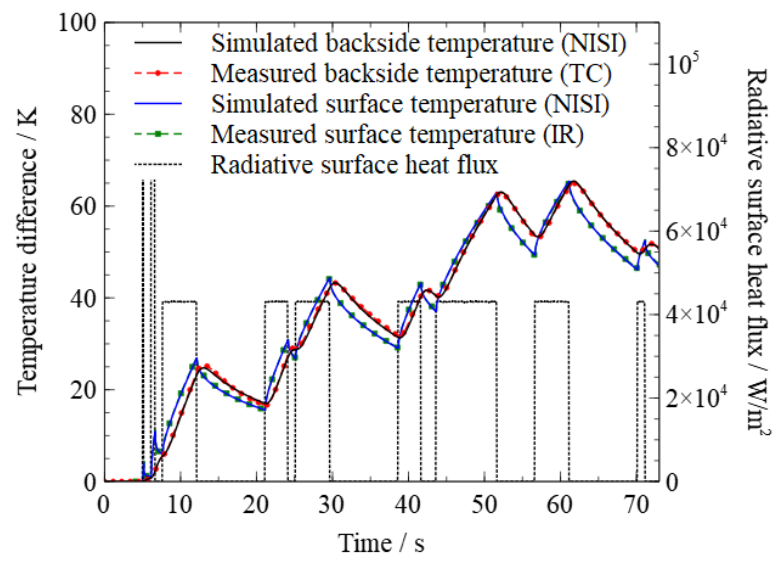

Figure 9. Example of the NISI identification for the case of $\dot{m}_{A}=205 \mathbf{g ~ m}^{-2} \mathbf{s}^{-1}$.

Additionally, the mathematical approach described in section II is used to calculate the thermal impulse responses of fluid and solid phases for various depths in the material. For the remainder of the study, the data 
obtained this way is denoted as simulation. The fluid impulse responses are subsequently used to calculate the transient pressure rise in the plenum due to surface heating. This effect has been studied in Refs. ${ }^{20,40}$ and is caused by an increase of the dynamic viscosity of the coolant gas due to an elevated temperature. The absolute fluid transient temperature at various depths is determined via the convolution

$$
T_{f}(x, t)=\int_{0}^{t} H_{f}(x, t-\tau) \cdot \dot{q}(x=0, \tau) \mathrm{d} \tau+T_{0}
$$

with the measured surface heat flux, $\dot{q}(x=0, t)$, of a given heating experiment. Subsequently, the fluid temperatures are used to calculate the dynamic viscosity using Sutherland's law ${ }^{47}$

$$
\mu_{f}=\mu_{\mathrm{ref}} \frac{T_{\mathrm{ref}}+C_{\mathrm{ref}}}{T_{f}+C_{\mathrm{ref}}}\left(\frac{T_{f}}{T_{\mathrm{ref}}}\right)^{3 / 2}
$$

with the nitrogen reference viscosity $\mu_{\text {ref }}=17.81 \cdot 10^{-6} \mathrm{Pas}$, Sutherland's constant $C_{\text {ref }}=111 \mathrm{~K}$ and the reference temperature $T_{\text {ref }}=300.55 \mathrm{~K}$. The pressure loss over the whole material depth is calculated numerically in a stepwise manner, by solving the one-dimensional Darcy-Forchheimer equation

$$
-\frac{\partial p}{\partial x}=\frac{\mu_{f}}{K_{D}} u_{m}+\frac{\rho_{f}}{K_{F}} u_{m}^{2},
$$

for which the material is split into 20 discrete regions. ${ }^{9}$ In this equation, $K_{D}$ is the Darcy-coefficient and $K_{F}$ is the Forchheimer-coefficient. The local densities and velocities at each depth are calculated with the ideal gas equation using the measured mass flow rate, the calculated local fluid temperature and the calculated local pressure.

The simulated transient plenum pressure rise and the simulated temperature impulse responses of surface and backside are subsequently compared with the experimental measurements. ${ }^{31}$ All thermophysical parameters of the material are known except for the volumetric heat transfer coefficient $h_{v}$. Therefore, only $h_{v}$ is varied until the best match between experiment and simulation is obtained for each impulse response or pressure signal respectively.

\section{Results}

\section{A. Solid Thermal Impulse Responses}

Figures 10 and 12 present the measured thermal impulse responses of the surface (infrared camera) and backside (thermocouple) that were obtained with the NISI-calibration method for mass flow fluxes between 0 and $244 \mathrm{~g} \mathrm{~m}^{-2} \mathrm{~s}^{-1}$. Figures 14 and 15 show a direct comparison between experiment and simulation for the maximum and zero blowing cases. As pointed out in section III.A, an increased mass flux leads to a lower solid impulse response, i. e. a higher cooling rate. In addition, a higher mass flux will also increase the volumetric heat transfer coefficient which will lead to a better cooling efficiency. Figures 11 and 13 show the corresponding solid thermal impulse responses of the simulation. Each impulse response has been fitted to its experimental counterpart, so that a volumetric heat transfer coefficient is obtained for each mass flux and each measurement technique.

Both surface and backside datasets show similar tendencies in absolute magnitude and in the temperature decrease for higher mass fluxes. However, discrepancies exist: The measured surface impulse responses show a more gradual temperature decrease at short times, whereas the simulation predicts a very steep decrease in the beginning and a delayed onset of the cooling effect. This is most likely due to the finite number of derivatives used in Eq. (20) and the limited frequency resolution of the infrared camera measurement $(30 \mathrm{~Hz})$. In addition, uncertainties in the thermophysical properties contribute to the mismatch. The impulse responses at later times show an excellent agreement between experiment and simulation. The maximum amplitude of the measured backside impulse response is slightly lower than the simulated data. Furthermore, the temperature drop immediately after the maximum is steeper in the experiment. Both effects suggest a higher heat loss at the backside which could arise through natural convection in the plenum or radiative heat loss. The finite thermocouple response time and uncertainties in the thermophysical parameters could also be a cause for the lower measured amplitude.

Furthermore, the simulation predicts an earlier influence of the cooling, i. e. the impulse responses for different mass fluxes start to spread earlier. A possible explanation is a delayed temperature measurement 


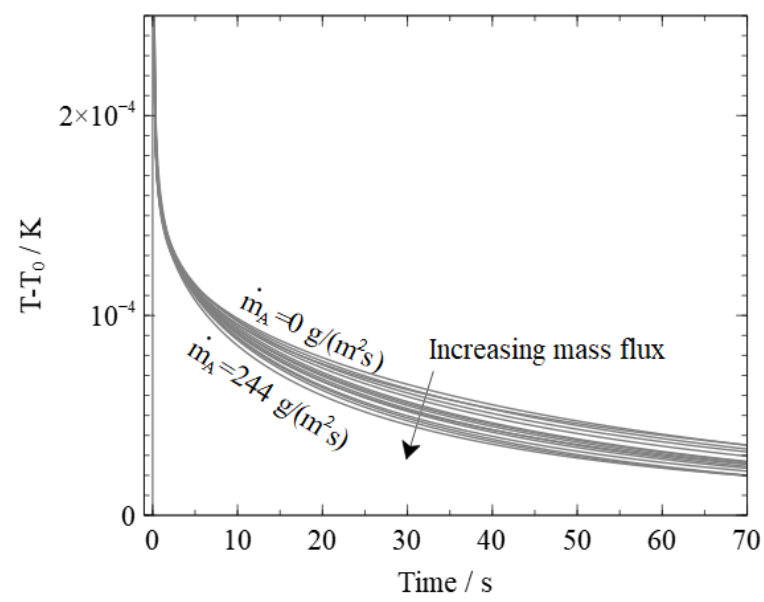

Figure 10. Measured thermal impulse responses of the solid material at $x=0$.

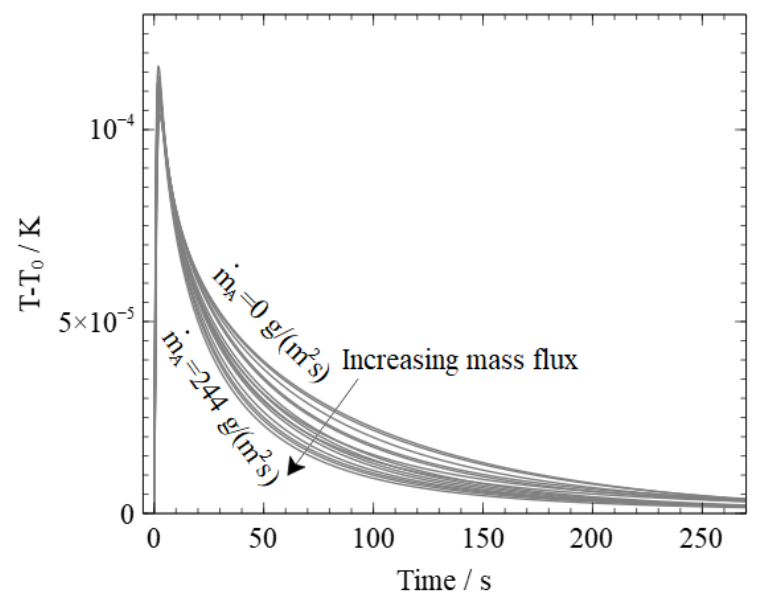

Figure 12. Measured thermal impulse responses of the solid material at $x=L$.

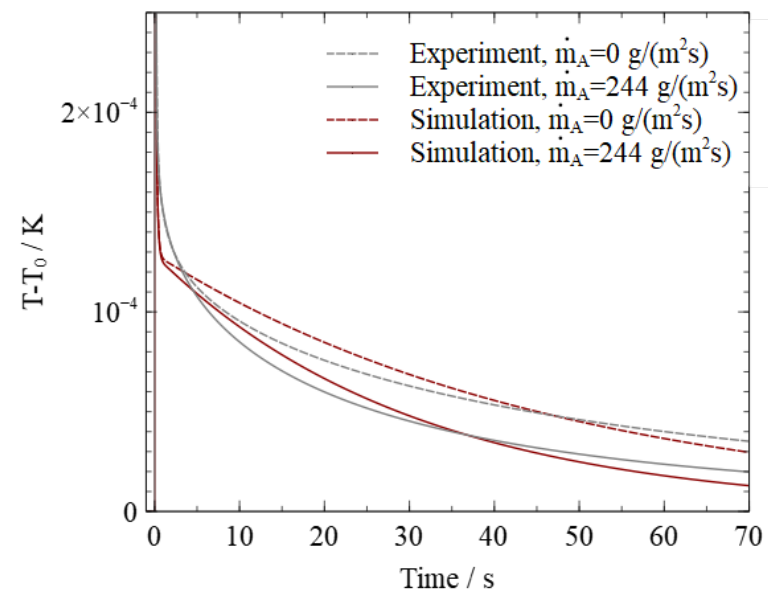

Figure 14. Measured and simulated thermal impulse responses of the solid material at $x=0$.

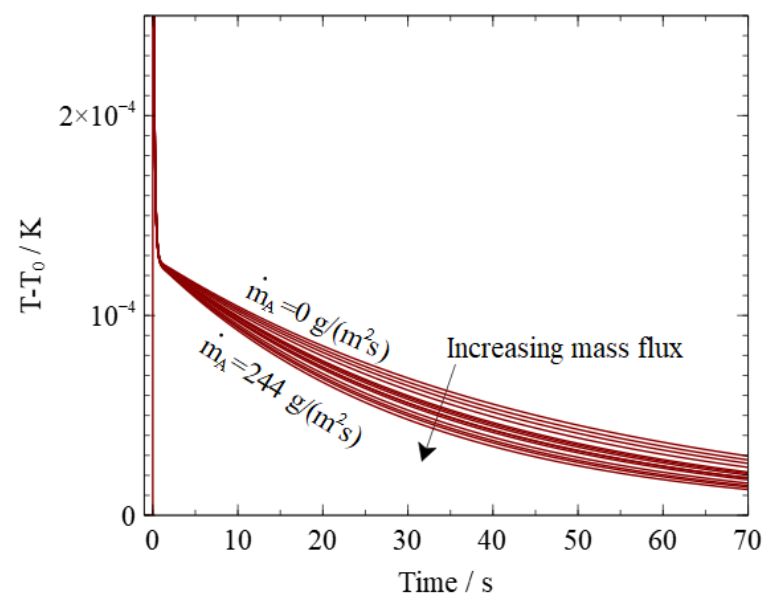

Figure 11. Simulated thermal impulse responses of the solid material at $x=0$.

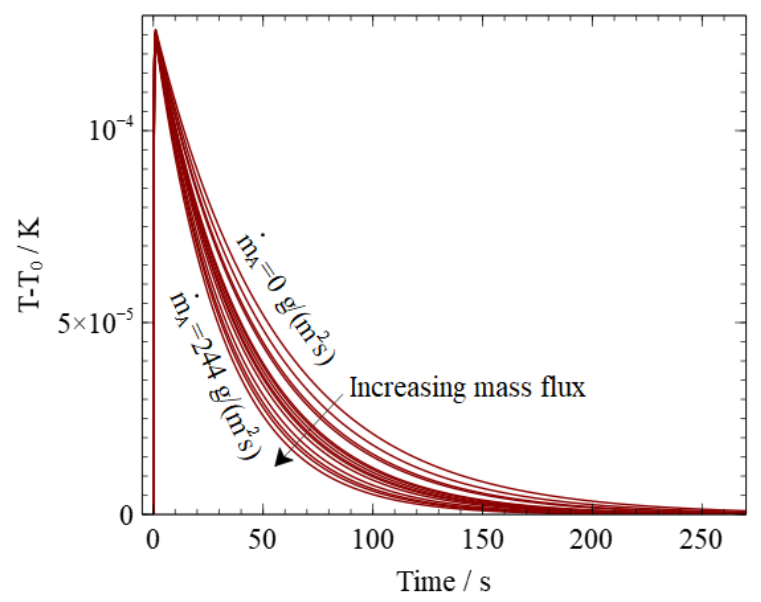

Figure 13. Simulated thermal impulse responses of the solid material at $x=L$.

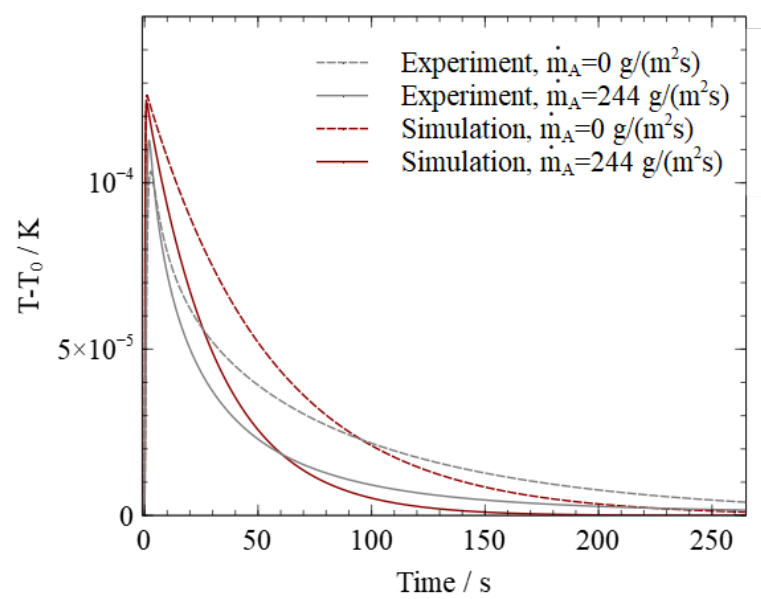

Figure 15. Measured and simulated thermal impulse responses of the solid material at $x=L$. 
in the experiment since the thermocouple is enveloped in ceramic glue which adds to the thermal mass of the specific measurement location. As with the surface measurements, the agreement between experiment and simulation is very good for later times and the cooling effect is clearly visible.

\section{B. Pressure Rise in the Plenum}

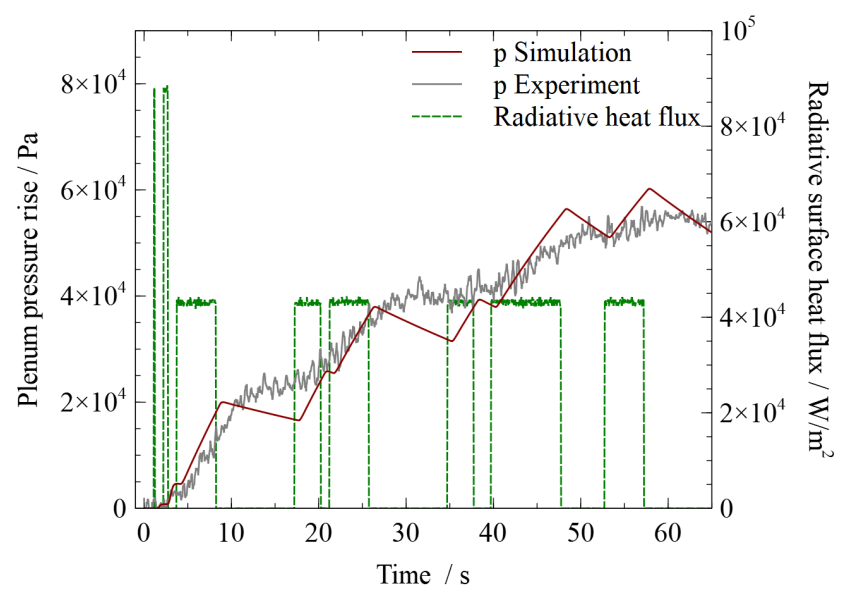

Figure 16. Plenum pressure rise for $\dot{m}_{A}=244 \mathrm{~g} \mathrm{~s}^{-1} \mathbf{m}^{-2}$ due to radiative surface heating.

Figure 16 shows the net transient radiative heat flux at the surface for a typical heating cycle. As discussed in section IV, the surface heating leads to a pressure rise in the plenum chamber. This pressure rise is a consequence of the experimental setup. The mass flow controller providing coolant to the plenum chamber ensures a constant mass flow which is set before the experiment. The heated fluid in the material leads to an increased blockage of the coolant gas because of the coolant viscosity increase. This leads to a higher pressure loss over the material (see Eq. (23)) which necessitates an increased plenum pressure to maintain the mass flow rate. Hence, the applied surface heat flux leads to a higher plenum pressure.

The case presented in Fig. 16, i. e. the pressure rise for a constant mass flux of $\dot{m}_{A}=244 \mathrm{~g} \mathrm{~m}^{-2} \mathrm{~s}^{-1}$, is in fair agreement with the simulated data. The amplitude of the pressure signal agrees well with the simulation, but the response to abrupt changes in heat flux shows a different behaviour. The simulation predicts a rapid change in plenum pressure after the onset of each pulse due to the almost instantaneous heating of the porous sample. The experimental data shows a much slower response and a clear delay between pressure rise and radiative heat flux which is significantly larger than the pressure sensor response time $(1 \mathrm{~ms})$. The delay is most likely caused by the mass flow regulator which is situated upstream of the plenum. The regulator keeps the mass flow constant by changing the pressure loss through it. However, as the blockage inside the porous material increases, the regulator has to adjust to the new situation. The transient heating and the inherently delayed reaction of the mass flow controller eventually lead to the very smoothed out experimental data presented in Fig 16. The causes of the pressure behaviour are further explored in the work of Hufgard et al. ${ }^{40}$

\section{Volumetric heat transfer coefficient}

Figure 17 shows the result of the fitting procedure that generated the data in Figs. 11, 13 and 16. An uncertainty analysis of the fitting routine has been carried out by employing the methodology of Moffat. ${ }^{48}$ The experimental uncertainties used in this analysis are summarised in Table $2 .{ }^{41,42}$ The uncertainties of the thermophysical parameters are based on their variance with temperature. The considered temperature interval is bounded by the maximum and minimum temperature encountered during the identification experiments.

The result shows a clear dependence of $h_{v}$ on the mass flux, as would be expected from the findings of the existing literature. ${ }^{24-29}$ Both datasets derived from temperature measurements show very good agreement for mass fluxes above $75 \mathrm{~g} \mathrm{~m}^{-2} \mathrm{~s}^{-1}$. For lower mass fluxes, the backside measurement data deviates. However, 


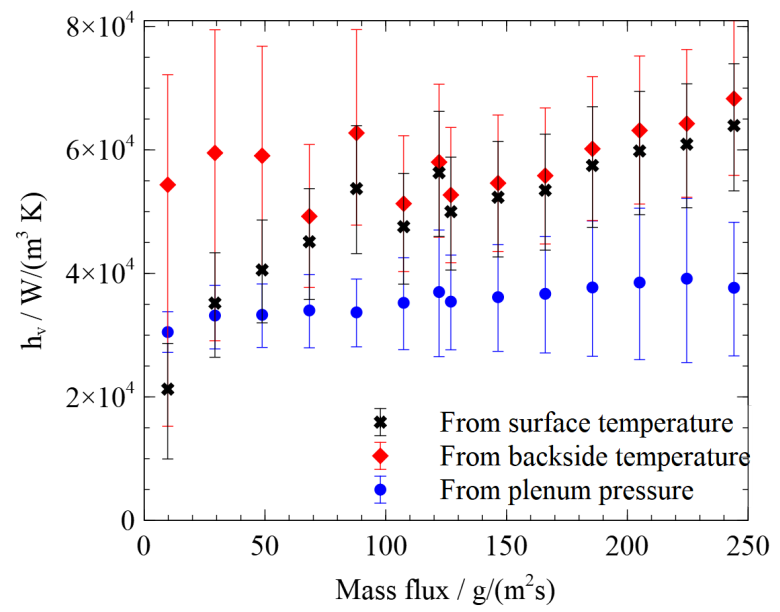

Figure 17. Volumetric heat transfer coefficient from temperature and plenum pressure measurements.

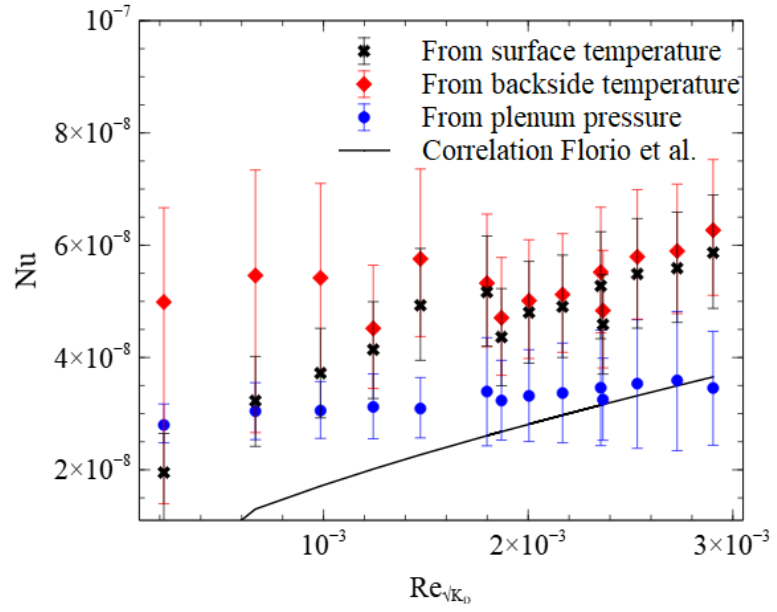

Figure 18. Nusselt number from temperature and plenum pressure measurements.

the respective uncertainties at those low mass fluxes are very large and still include the surface temperature result. The main cause for the large uncertainty is the mass flux. The increased uncertainty for the backside measurement again clearly shows the ill-conditioned nature of an inverse heat conduction problem, i. e. the backside impulse response measurement is far less direct as the heat has to be conducted through the entire depth of the material which leads to a larger uncertainty. ${ }^{49}$ The data obtained from the plenum pressure measurement agrees well with the surface temperature dataset at lower mass fluxes and shows significant discrepancies at higher mass fluxes. It also suggests an increase of $h_{v}$ with increasing $\dot{m}_{A}$, however at a lower rate. A possible explanation of the discrepancy could be due to undetected leaks in the system that are more prevalent at higher mass flow rates.

Table 2. Uncertainty of the measurement results.

\begin{tabular}{lc}
\hline \hline Parameter & Uncertainty \\
$K_{D}$ & $2 \%$ \\
$K_{F}$ & $25 \%$ \\
$c_{p, s}$ & $10 \%$ \\
$k_{s}$ & $5 \%$ \\
$k_{f}$ & $10 \%$ \\
$\dot{m}$ & $6 \mathrm{mg} \mathrm{s}^{-1}$ \\
$p_{\text {plenum }}$ & $0.1 \mathrm{bar}$ \\
$T_{\text {ambient }}$ & $5 \mathrm{~K}$ \\
$P_{\text {laser }}$ & $10 \%$ \\
\hline \hline
\end{tabular}

The work of Florio et al. has been used to assess the Nusselt number of the measurement data via ${ }^{23}$

$$
\mathrm{Nu}=\frac{h_{v} K_{D}}{k_{f}} .
$$

The respective Reynolds number is calculated by

$$
\operatorname{Re}_{\sqrt{K_{D}}}=-\frac{\rho_{f} K_{D}^{1.5} \Delta p}{\mu_{f}^{2} \phi L},
$$

with the pressure loss $\Delta p$ over the porous material. This pressure difference is negative per definition which explains the minus in Eq. (25). Florio et al. give various correlations for existing polymer composite 
materials. ${ }^{23}$ Among these, one correlation,

$$
\mathrm{Nu}=2.22 \cdot 10^{6}\left(\operatorname{Re}_{\sqrt{K_{D}}}\right)^{0.703}
$$

has been used to assess the Nusselt number for C/C ceramic materials. ${ }^{16}$ The same correlation is evaluated at the measurement Reynolds numbers of this work and compared against the experimentally obtained values in Fig. 18. The Nusselt numbers for $\mathrm{ZrB}_{2}$ are significantly larger than the values obtained with Eq. (26), especially for low Reynolds numbers. For high Reynolds numbers, a close agreement between the Nusselt numbers obtained from the plenum pressure measurement and the correlation exists.

In particular the data derived from surface temperature shows a behaviour, which corresponds to the power law in Eq (26), as expected for flows through porous ceramics. ${ }^{27}$ A conclusion that can be drawn from this comparison is that the partially sintered $\mathrm{ZrB}_{2}$ ceramic performs very well at low Reynolds numbers which makes them an ideal candidate for transpiration cooling applications where lower mass fluxes are required.

\section{Conclusion}

A semi-analytical solution of the coupled partial differential equations for porous media in thermal nonequilibrium is presented which allows the calculation of the thermal impulse response of fluid and solid phase. The analysis of the obtained impulse responses for different mass fluxes shows a significant sensitivity with regards to the volumetric heat transfer coefficient. A comparison between experimentally measured impulse responses and the respective simulated values allows the determination of the volumetric heat transfer coefficient. Furthermore, the efficiency of solid-fluid heat transfer also influences the transient behaviour of the plenum pressure. The magnitude of the plenum pressure rise is therefore also used as a means to infer the volumetric heat transfer coefficient. The thermal impulse response of the backside and the surface of a porous $\mathrm{ZrB}_{2}$ sample yields volumetric heat transfer coefficients between $h_{v}=2.1 \cdot 10^{4}$ and $6.8 \cdot 10^{4} \mathrm{~W} \mathrm{~m}^{-3} \mathrm{~K}^{-1}$ for mass fluxes between $\dot{m}_{A}=10$ and $244 \mathrm{~g} \mathrm{~m}^{-2} \mathrm{~s}^{-1}$. The transient pressure rise in the plenum during an experiment yields volumetric heat transfer coefficients of $h_{v}=3.1 \cdot 10^{4}$ and $3.9 \cdot 10^{4} \mathrm{~W} \mathrm{~m}^{-3} \mathrm{~K}^{-1}$ for the same mass flux range. Three distinctly different measurement datasets have been used independently in the determination of the volumetric heat transfer coefficient, i. e. thermocouple instrumentation, infrared thermography and plenum pressure. The close agreement between the obtained measurement outcome shows that the developed model is suitable for the analysis of porous candidate materials for transpiration cooling systems. The developed model is found to be suitable for solving the inverse heat conduction problem of transpiration cooled materials and can be used to assess the efficiency of the solid-fluid heat transfer of porous media.

\section{Acknowledgments}

The help and dedicated attention to detail of Greg King is greatly acknowledged. The authors would like to extend their gratitude towards the entire hypersonics group and the laboratory technical staff. The authors additionally thank Laura Larrimbe, Daniel Glymond and Luc Vandeperre from Imperial College London for providing the material samples, the respective thermophysical properties as well as their advice on the experiment.

\section{References}

${ }^{1}$ Dittert, C., Selzer, M., and Böhrk, H., "Flowfield and Pressure Decay Analysis of Porous Cones," AIAA Journal, Vol. 55, No. 3, May 2018, pp. 874-882.

${ }^{2}$ Esser, B., Gülhan, A., Reimer, T., and Petkov, I., "Experimental Verification of Thermal Management Concepts for Space Vehicles," 8th European Symposium on Aerothermodynamics for Space Vehicles, No. 91674 in Conference Proceedings online, 2015, pp. 1-8.

${ }^{3}$ Mohammed Ibrahim, S., Vivek, P., and Reddy, K. P. J., "Experimental Investigation on Transpiration Cooling Effectiveness for Spacecraft Entering Martian Atmosphere," AIAA Journal, Vol. 54, No. 9, May 2018, pp. 2922-2926.

${ }^{4}$ Böhrk, H., Elsässer, H., and Weihs, H., "Flight Data from the faceted TPS on Shefex II," 8th European Symposium on Aerothermodynamics for Space Vehicles, 2015.

${ }^{5}$ Kuhn, M. and Hald, H., "Application of Transpiration Cooling for Hot Structures," RESPACE - Key Technologies for Reusable Space Systems, edited by A. Gülhan, Springer Berlin Heidelberg, Berlin, Heidelberg, 2008, pp. 82-103. 
${ }^{6}$ Liu, Y.-Q., Jiang, P., Jin, S.-S., and Sun, J.-G., "Transpiration cooling of a nose cone by various foreign gases," International Journal of Heat and Mass Transfer, Vol. 53, Nov. 2010, pp. 5364-5372.

${ }^{7}$ Basore, K. D., Selzer, M., Wheatley, V., Boyce, R. R., Mee, D. J., Capra, B. R., Kuhn, M., and Brieschenk, S., "Performance comparison of distributed injection methods for hypersonic film-cooling," 20th Australasian Fluid Mechanics Conference, Australasian Fluid Mechanics Society, Perth, WA, December 2016.

${ }^{8}$ Anderson, J. D., Hypersonic and High-Temperature Gas Dynamics, Second Edition, AIAA Education Series, 2006.

${ }^{9}$ Langener, T., Wolfersdorf, J. V., and Steelant, J., "Experimental Investigations on Transpiration Cooling for Scramjet Applications Using Different Coolants," AIAA Journal, Vol. 49, No. 7, May 2011, pp. 1409-1419.

${ }^{10}$ Tanno, H., Komuro, T., Itoh, K., Kuhn, M., Petkov, I., and Esser, B., "Transpiration cooling experiments in free-piston shock tunnel HIEST," 8th European Workshop on Thermal Protection Systems and Hot Structures, July 2016.

${ }^{11}$ Kays, W. M., "Heat transfer to the transpired turbulent boundary layer," International Journal of Heat and Mass Transfer, Vol. 15, No. 5, May 1972, pp. 1023-1044.

12 Jiang, P., Yu, L., Sun, J.-G., and Wang, J., "Experimental and numerical investigation of convection heat transfer in transpiration cooling," Applied Thermal Engineering, Vol. 24, June 2004, pp. 1271-1289.

${ }^{13}$ Guelhan, A. and Braun, S., "An experimental study on the efficiency of transpiration cooling in laminar and turbulent hypersonic flows," Experiments in Fluids, Vol. 50, No. 3, March 2011, pp. 509-525.

${ }^{14}$ Otsu, H., Fujita, K., and Ito, T., "Application of the Transpiration Cooling Method for Reentry Vehicles," No. 0 in Aerospace Sciences Meetings, American Institute of Aeronautics and Astronautics, Oct. 2007.

${ }^{15}$ Ewenz Rocher, M., Hermann, T., McGilvray, M., Ifti, H. S., Hufgard, F., M., E., Meindl, A., Loehle, S., and Zander, F., "Testing a Transpiration Cooled Zirconium-Di-Boride sample in the Plasma Tunnel at IRS," 22nd AIAA International Space Planes and Hypersonics Systems and Technologies Conference, 2019.

${ }^{16}$ Boehrk, H., Piol, O., and Kuhn, M., "Heat Balance of a Transpiration-Cooled Heat Shield," Journal of Thermophysics and Heat Transfer, Vol. 24, No. 3, May 2010, pp. 581-588.

${ }^{17}$ Schweikert, S., von Wolfersdorf, J., Selzer, M., and Hald, H., "Experimental Investigation on Velocity and Temperature Distributions of Turbulent Cross Flows over Transpiration Cooled C/C-Wall Segments," 5th European Conference for Aeronautics and Space Sciences (EUCASS), June 2013.

${ }^{18}$ Schweikert, S., von Wolfersdorf, J., Selzer, M., and Hald, H., "Characterization of Actively Cooled Porous C/C Wall Segments According to Pressure Loss and Internal Temperature Distribution," 7th European Workshop on Thermal Protection Systems \&3 Hot Structures, 2013.

${ }^{19}$ Dahmen, W., Müller, S., Rom, M., Schweikert, S., Selzer, M., and von Wolfersdorf, J., "Numerical boundary layer investigations of transpiration-cooled turbulent channel flow," International Journal of Heat and Mass Transfer, Vol. 86, July 2015, pp. 90-100.

${ }^{20}$ Loehle, S., Schweikert, S., and von Wolfersdorf, J., "Method for Heat Flux Determination of a Transpiration-Cooled Wall from Pressure Data," Journal of Thermophysics and Heat Transfer, Vol. 30, No. 3, May 2016, pp. 567-572.

${ }^{21}$ Scoggins, J., The Development of a Thermochemical Nonequilibrium Ablation and Pyrolysis Model for Carbon-Phenolic Thermal Protection Systems, Master's thesis, North Carolina State University, 2011.

${ }^{22}$ Clark, R. K., "An analysis of a charring ablator with thermal non-equilibrium, chemical kinetics and mass transfer," Tech. Rep. TN D-7180, NASA, 1973.

${ }^{23}$ Florio, J., Henderson, J. B., Test, F. L., and Hariharan, R., "Characterization of Forced Convection Heat Transfer in Decomposing, Glass-Filled Polymer Composites," Journal of Composite Materials, Vol. 25, No. 11, Sept. 1991, pp. $1515-1539$.

${ }^{24}$ Jeng, T.-M., Wang, M.-P., Hwang, G.-J., and Hung, Y.-H., "A new semi-empirical model for predicting heat transfer characteristics in porous channels," Experimental Thermal and Fluid Science, Vol. 29, No. 1, Dec. 2004, pp. 9-21.

${ }^{25}$ Mayer, B., Gomaa, H., Weigand, B., and Zudin, Y. B., "An analytical model to evaluate heat transfer characteristics in porous media by a periodic quasi steady-state technique," ISROMAC 2012 - 14th International Symposium on Transport Phenomena and Dynamics of Rotating Machinery, 012012.

${ }^{26}$ Younis, L. B. and Viskanta, R., "Experimental determination of the volumetric heat transfer coefficient between stream of air and ceramic foam," International Journal of Heat and Mass Transfer, Vol. 36, No. 6, Jan. 1993, pp. $1425-1434$.

${ }^{27}$ Dietrich, B., "Heat transfer coefficients for solid ceramic sponges - Experimental results and correlation," International Journal of Heat and Mass Transfer, Vol. 61, June 2013, pp. 627-637.

${ }^{28}$ Florio, J., Henderson, J. B., Test, F. L., and Hariharan, R., "A study of the effects of the assumption of local-thermal equilibrium on the overall thermally-induced response of a decomposing, glass-filled polymer composite," International Journal of Heat and Mass Transfer, Vol. 34, No. 1, Jan. 1991, pp. 135-147.

${ }^{29} \mathrm{Fu}$, X., Viskanta, R., and Gore, J. P., "Measurement and correlation of volumetric heat transfer coefficients of cellular ceramics," Experimental Thermal and Fluid Science, Vol. 17, No. 4, Aug. 1998, pp. 285-293.

${ }^{30}$ Wang, H. and Guo, L., "Volumetric Convective Heat Transfer Coefficient Model for Metal Foams," Heat Transfer Engineering, Feb. 2018, pp. 1-12.

${ }^{31}$ Schweikert, S., von Wolfersdorf, J., Selzer, M., and Hald, H., "Transient Temperature Characteristics of Transpiration Cooled Material," Sonderforschungsbereich/transregio 40 - annual report, Institute of Aerospace Thermodynamics, University of Stuttgart, 2015.

${ }^{32}$ Beck, J. V., Blackwell, B., and Charles R. St. Clair, J., Inverse Heat Conduction: Ill-Posed Problems, Wiley-Interscience, 1985.

${ }^{33}$ Oldfield, M., "Impulse Response Processing of Transient Heat Transfer Gauge Signals," Journal of Turbomachinery, April 2008.

${ }^{34}$ Loehle, S. and Fuchs, U., "Heat Flux Calibration Measurement Using the Noninteger System Identification Method for Cooled Surfaces," Journal of Thermophysics and Heat Transfer, Vol. 25, No. 2, May 2011, pp. 213-217.

${ }^{35}$ Baghban, M., Shams, Z., and Ebrahimifakhar, A., "Inverse Analysis of a Porous Fin to Estimate Time-Dependent Base Temperature," Journal of Thermophysics and Heat Transfer, Vol. 32, No. 1, May 2018, pp. 27-34. 
${ }^{36}$ Spiga, G. and Spiga, M., "A rigorous solution to a heat transfer two phase model in porous media and packed beds," International Journal of Heat and Mass Transfer, Vol. 24, No. 2, Feb. 1981, pp. 355-364.

${ }^{37}$ Gaver, D. P., "Observing Stochastic Processes, and Approximate Transform Inversion," Operations Research,, Vol. 14, No. 3, 1966, pp. $444-459$.

${ }^{38}$ Stehfest, H., "Algorithm 368: Numerical Inversion of Laplace Transforms [D5]," Commun. ACM, Vol. 13, No. 1, Jan. 1970, pp. 47-49.

${ }^{39}$ Loehle, S., "Derivation of the non-integer system identification method for the adiabatic boundary condition using Laplace transform," International Journal of Heat and Mass Transfer, Vol. 115, Dec. 2017, pp. 1144-1149.

${ }^{40}$ Hufgard, F., Loehle, S., von Wolfersdorf, J., Steelant4, J., Hermann, T., and McGilvray, M., "Analysis of Porous Materials for Transpiration-Cooled Heat Flux Sensor Development," International Conference on High-Speed Vehicle Science Technology, Moscow, Russia, 2018.

${ }^{41}$ Chase, M. W., of Standards, N. I., and (U.S.), T., NIST-JANAF thermochemical tables, American Chemical Society ; American Institute of Physics for the National Institute of Standards and Technology, [Washington, D.C.]; Woodbury, N.Y., 1998.

${ }^{42}$ Ifti, H. S., Hermann, T., and McGilvray, M., "Flow Characterisation of Transpiring Porous Media for Hypersonic Vehicles," 22nd AIAA International Space Planes and Hypersonics Systems and Technologies Conference, Orlando, Florida, 2018.

${ }^{43}$ Balat-Pichelin, M., Bêche, E., Sciti, D., and Alfano, D., "Emissivity, catalycity and microstructural characterization of ZrB2-SiCfiber based UHTC at high temperature in a non-equilibrium air plasma flow," Ceramics International, Vol. 40, No. 7, Part A, Aug. 2014, pp. 9731-9742.

${ }^{44}$ Battaglia, J.-L., Cois, O., Puigsegur, L., and Oustaloup, A., "Solving an inverse heat conduction problem using a noninteger identified model," International Journal of Heat and Mass Transfer, Vol. 44, No. 14, July 2001, pp. 2671-2680.

${ }^{45}$ Loehle, S. and Fuchs, U., "Theoretical Approach to Surface Heat Flux Distribution Measurement from In-Depth Temperature Sensors," Journal of Thermophysics and Heat Transfer, Vol. 26, No. 2, May 2012, pp. 352-356.

${ }^{46}$ Hufgard, F., Loehle, S., von Wolfersdorf, J., Fasoulas, S., Rocher, M. E., Hermann, T., McGilvray, M., and Steelant, J., "Surface Heat Flux Measurement in Transpiration-Cooled Porous Materials using Plenum Pressure Data," AIAA Science and Technology Forum and Exposition, San Diego, CA, 2019.

${ }^{47}$ White, F., Viscous Fluid Flow. 2nd Edition, McGraw-Hill, 1991.

${ }^{48}$ Moffat, R. J., "Describing the uncertainties in experimental results," Experimental Thermal and Fluid Science, Vol. 1, No. 1, Jan. 1988, pp. 3-17.

${ }^{49}$ Fuchs, U., Loehle, S., and Fasoulas, S., "Theoretical Stability Analysis for Inverse Heat Conduction Problems Using the Condition Number," Journal of Thermophysics and Heat Transfer, Vol. 29, No. 3, Oct. 2015, pp. 473-481. 